\title{
Synthesis of ZnO Nanoparticles by using Rosmarinus officinalis Extract and their Application for Methylene bleu and Crystal violet Dyes Degradation under Sunlight irradiation
}

\author{
Tahani Al-Garni, Naaser A.Y. Abduh, Abdullah Al Kahtani, Ahmed Aouissi* \\ Department of Chemistry, King Saud University, P.O. Box 2455, Riyadh-11451, \\ Saudi Arabia \\ Chemistry Department, College of Science, King Saud University, Riyadh, Saudi Arabia \\ * Corresponding Author. E-mail: aouissia@KSU.EDU.SA \\ Tel.: +9661 4675958; Fax: +96614675992.
}

\begin{abstract}
Zinc oxide ( $\mathrm{ZnO}$ ) nanoparticles (NPs) were synthesized using Rosmarinus officinalis leaf extract at $80^{\circ} \mathrm{C}(\mathrm{ZnO}-80)$ and $180^{\circ} \mathrm{C}(\mathrm{ZnO}-180)$. The biosynthesized $\mathrm{ZnO}$ NPs were characterized and their photocatalytic activity was evaluated for the degradation of methylene blue (MB) and crystal violet (CV) under sunlight irradiation. The results of the characterizations by XRD, TEM and SEM showed that the size of the NPs of ZnO-80 was smaller than that of $\mathrm{ZnO}-180$ which exhibited flakier agglomerated spherical structures. Photocatalytic tests showed $\mathrm{ZnO}-80$ which was prepared by a cheap and easy procedure compared to $\mathrm{ZnO}-180$ effectively degrades $\mathrm{MB}$ and $\mathrm{CV}$ dyes under sunlight. The superior performance of $\mathrm{ZnO}-80$ over $\mathrm{ZnO}-180$ can be explained by the differences in their textural properties. This is because $\mathrm{ZnO}-80$ has a smaller crystallite size, a specific surface area and a higher pore volume than $\mathrm{ZnO}-180$. Fourier-transform infrared spectroscopy (FTIR) analyzes revealed that both samples contained an adsorbed carboxylate group $\left(\mathrm{COO}^{-}\right)$, and accordingly a mechanism was proposed for the formation of $\mathrm{ZnO}$ NPs that include the carboxyl group.
\end{abstract}

Keywords: dye; ZnO; NPs; leaf extract; Rosmarinus officinalis; photodegradation; methylene bleu; crystal violet

\section{Introduction}

The removal of organic contaminants from wastewater, and especially those resulting from dyes, remains a major concern for several countries. Indeed, environmental contamination caused by dyes leads to health problems due to their toxicity [1-5]. Dyes are organic 
compounds used in various industries, such as textiles, paper, plastics, leather plastics, food, printing and pharmaceuticals, electroplating and agriculture [6-8]. It should be noted that these industries use considerable quantities of water and consequently their wastewater containing dyes in significant quantities are discharged into natural waters. Some of these dyes are toxic, mutagenic and carcinogenic [10]. Moreover, these dyes, by preventing the penetration of solar light into water, reduce photosynthetic activity and thus cause a disturbance of the aquatic equilibrium [11]. Il should be mentioned that without appropriate treatments, these dyes can remain in the natural water for a long time [12]. This is why various physical methods such as adsorption [13, 14], coagulation [15, 16], biodegradation $[17,18]$, and various chemical methods such as chlorination, ozonation, etc. [19] have been used to reduce the environmental effects of dyes. However, physical and biological methods do not remove pollutants; they only transform them into another phase. As for chemical methods, they have the drawback of using strong oxidants such as chlorine and ozone which are themselves pollutants. The most suitable way to eliminate this waste is their degradation by photocatalysis. In fact, dyes can be degraded in the presence of photocatalyst when irradiated with visible light due to their absorption in the visible region.

In the last decades, particular interest has been focused on heterogeneous photodegradation by metal oxides because of their wide use in organic synthesis and their environmental applications [20, 21]. Among the different metal oxides used, it has been reported that titanium dioxide $\left(\mathrm{TiO}_{2}\right)$ and zinc oxide $(\mathrm{ZnO})$ are the most chemically stable and are not toxic [22-24]. This is what explains their applications in different fields $[25,26]$. $\mathrm{TiO}_{2} \mathrm{has}$ been widely studied as a photocatalyst and found to have very good photocatalytic activity. However, its application using solar energy is strongly limited by its wide forbidden band $(3.2 \mathrm{eV})$ and its low quantum efficiency [27]. As for $\mathrm{ZnO}$, it is a type of semiconductor which has a wide direct band gap (3.37 eV), a large excitation binding energy (60 meV) [28]. In addition, $\mathrm{ZnO}$ not only has anti-fouling and antibacterial properties, but also good photocatalytic activity [29]. In addition, $\mathrm{ZnO}$ has been shown to exhibit high absorption efficiency over a large fraction of the solar spectrum compared to $\mathrm{TiO}_{2}$ [30]. Taking into account these properties mentioned and the non-toxic nature, good environmental stability, 
strong oxidizing power, $\mathrm{ZnO}$ can be considered as a suitable alternative to $\mathrm{TiO}_{2}$ photocatalyst.

Sunlight is an abundantly available source of energy and its irradiation can be exploited to develop an economically process for the photodegradation of pollutants. In the present study, the degradation of two dyes, methylene blue (MB) and crystal violet (CV) under sunlight irradiation by $\mathrm{ZnO}$ NPs biosynthesized at $80^{\circ} \mathrm{C}$ and $180^{\circ} \mathrm{C}$ was investigated.

\section{Materials and methods}

\subsection{Plant Materials}

The healthy wild Rosmarinus leaves were collected from Abha region in southern of Saudi Arabia. Zinc nitrate hexahydrate and sodium hydroxide, methylene blue (MB), crystal violet from BHD. All the chemicals used without further purification.

\subsection{Preparation of leaf extract}

The collected fresh and healthy leaves of Rosmarinus were washed with deionized water, shadow dried for 2-3 weeks and then powdered using mixer grinder. For the preparation of aqueous leaf extract (ALE) solution, $10 \mathrm{~g}$ of powder dissolved in $100 \mathrm{ml}$ of deionized water, boiled at $60{ }^{\circ} \mathrm{C}$ for $15 \mathrm{~min}$ to kill the pathogens in ALE solution. After cooling, ALE solution was filtered using filter paper and stored at $4{ }^{\circ} \mathrm{C}$ for further use.

\subsection{Synthesis of ZnO NPs using Rosmarinus leaf extract.}

$\mathrm{ZnO}$ NPs were prepared by adding zinc nitrate hexahydrate to aqueous leaf extract solution (ALE). Two samples were prepared; the first sample was prepared by adding $18 \mathrm{ml}$ of $\mathrm{NaOH}$ $(2 \mathrm{M})$ to a solution constituted of $5 \mathrm{~g} \mathrm{Zn}\left(\mathrm{NO}_{3}\right)_{2} \cdot 6 \mathrm{H}_{2} \mathrm{O}$ in $30 \mathrm{ml}$ of the plant extract contained in an Erlenmeyer flask. The Erlenmeyer flask containing the resulting mixture was closed and then heated to $80{ }^{\circ} \mathrm{C}$ with stirring for 3 hours. The catalyst thus prepared was denoted $\mathrm{ZnO}-80$. The second sample was prepared in the same way but instead of being heated in the Erlenmeyer flask, it was transferred to a Teflon lined steel autoclave and heated at 180 
${ }^{\circ} \mathrm{C}$ for 3 hours. The catalyst thus prepared was denoted $\mathrm{ZnO}-180$. In both cases the obtained white precipitate was separated and washed several times with a solution of distilled water: ethanol (3:1). Then, it was left in the oven at $80{ }^{\circ} \mathrm{C}$ overnight and calcined in a furnace at $500{ }^{\circ} \mathrm{C}$ for $3 \mathrm{~h}$. An illustrative scheme is given in Figure 1.

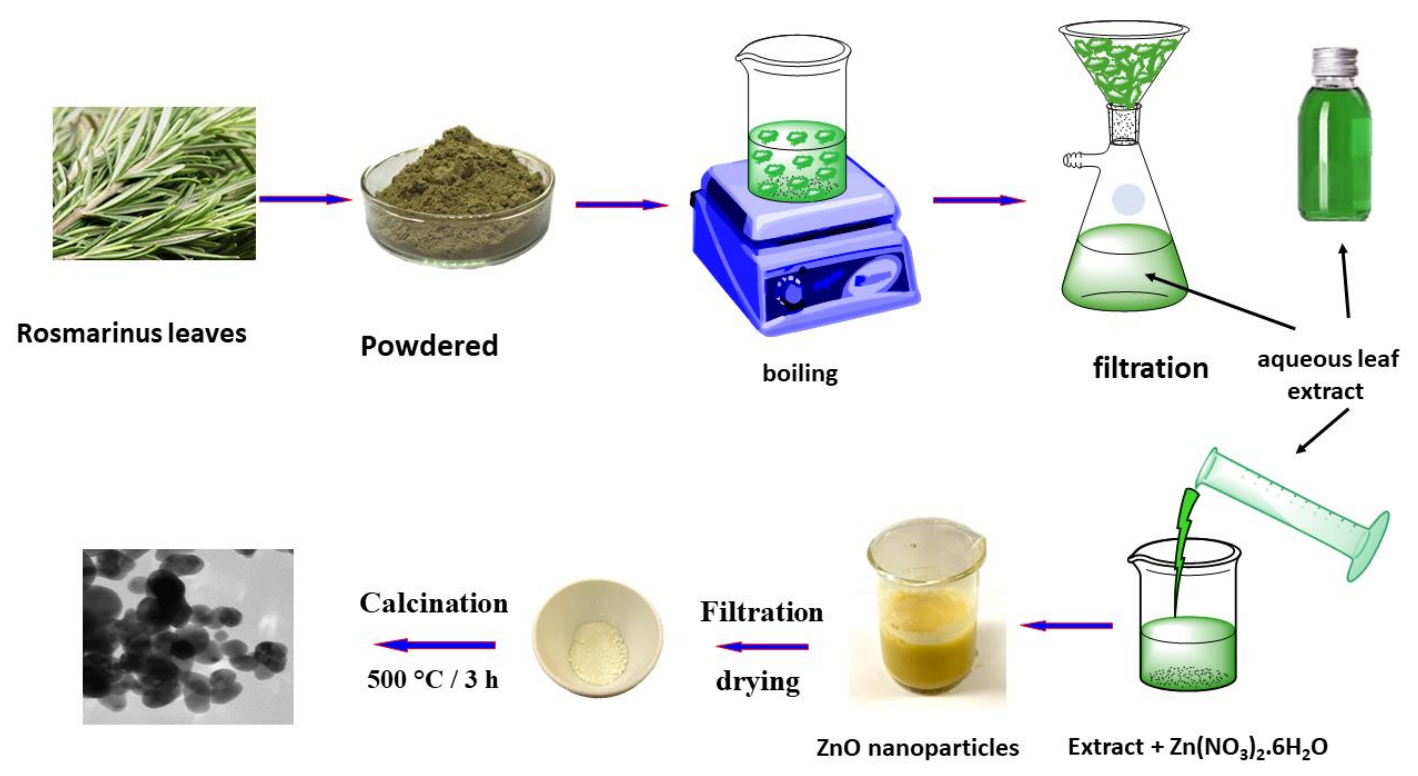

Figure 1. Schematic presentation of $\mathrm{ZnO}-\mathrm{NPs}$ synthesis using Rosmarinus officinalis leaf extract.

\subsection{Photocatalyic test}

$10 \mathrm{mg}$ of photocatalyst and $10 \mathrm{ml}$ of $10 \mathrm{ppm}$ of dyes was suspended in a bottle and the mixture was stirred in the dark to evaluate adsorption-desorption equilibrium. The photodegradation was carried under sun light irradiation in a clear day of September (temperature $40{ }^{\circ} \mathrm{C}$ ) at Riyadh, Longitude 46:625 Width 24:727. The resulting suspension was centrifuged at $3000 \mathrm{rpm}$ for 5 minutes before measuring the absorbance using UV-Vis spectrophotometer. The photo-degradation rate of methylene blue (MB) was calculated by the following Eq. (1) [31]:

Degradation $\%=\frac{A_{0}-A_{t}}{A_{0}}$ 
where $A_{0}$ is the initial absorbance of $\mathrm{MB} ; A_{t}$ is the absorbance of the solution after sunlight irradiation at time $t$.

\subsection{Characterization of the catalysts}

Infrared spectra were recorded with an infrared spectrometer GENESIS II- FTIR (4000-400 $\mathrm{cm}^{-1}$ ) using the $\mathrm{KBr}$ Pellet technique. X-ray diffraction (XRD) measurements were carried out employing an Ultima IV, X-ray Rigaku difractometer using $\mathrm{Cu}-\mathrm{K} \alpha$ radiation. UV-Vis characterization was achieved by means of double beam UV-Vis spectrophotometer (Philips 8800). Catalysts Surface morphology was analyzed by using a JSM-7600F (JEOL Ltd, Japan) Transmission electron microscopy (TEM). Thermogravimetric Analysis (TGA) were performed using a Netzsch Thermogravimetric analyzer TGA model SAT 449 F3.

The specific surface area (B.E.T), pore volume and average pore diameter of the fresh and used catalyst was measured in Micromeritics Tristar II 3020 surface area and porosity analyzer.

\section{Results and discussion}

\subsection{Catalysts Characterization}

\subsubsection{FTIR}

FTIR spectra of $\mathrm{ZnO}$ NPs synthesized at $80^{\circ} \mathrm{C}(\mathrm{ZnO}-80)$ and at $180^{\circ} \mathrm{C}(\mathrm{ZnO}-180)$ as well as the Rosmarinus leaf extract used for their synthesis are shown in Figure 2. The FTIR spectrum of the leaf extract showed the bands at 605, 758, 1075, 1242, 1425, 1612, 2931, and $3389 \mathrm{~cm}-1$ in the region of $400 \mathrm{~cm}^{-1}$ to $4000 \mathrm{~cm}^{-1}$. The $\mathrm{O}-\mathrm{H}$ stretch band is attributed to the hydroxyl groups of phenolic compounds and $\mathrm{N}-\mathrm{H}$ stretching vibration of group $\mathrm{NH}_{2}$ $[32,33]$. The peak at $2931 \mathrm{~cm}^{-1}$ is assigned to $\mathrm{C}-\mathrm{H}$ stretching vibrations to $\mathrm{CH}_{3}$ and $\mathrm{CH}_{2}$ [34]. The peak at $1612 \mathrm{~cm}^{-1}$ is assigned to Carbonyl $(-\mathrm{C}=\mathrm{O})$ group stretching vibration, $\mathrm{C}$ $\mathrm{N}$ stretching and $\mathrm{COO}^{-}$antisymemetric stretching [32]. The peak at $1425 \mathrm{~cm}^{-1}$ is assigned to $\mathrm{C}-\mathrm{O}$ stretching vibration (amide) and C-C stretching from phenyl groups and carboxylate $\mathrm{COO}^{-}$symmetric stretching [35]. The peak at 1075 is assigned to $\mathrm{C}-\mathrm{O}$ stretching vibration $[36,37]$. The spectrum of ZnO-80 NPs samples showed the bands at 416, $490 \mathrm{~cm}^{-1}$ and 1369 
$\mathrm{cm}^{-1}$. Similarly, the spectrum of ZnO-180 showed the bands at 420 and $492 \mathrm{~cm}^{-1}$ and 1383 $\mathrm{cm}^{-1}$. The pair of bands observed at 416 and $490 \mathrm{~cm}^{-1}$ and at 420 and $492 \mathrm{~cm}^{-1}$ are assigned to the tensile bond of $\mathrm{ZnO}$ and the oxygen vacancies in $\mathrm{ZnO}$ respectively. These results are in agreement with those reported in the literature [38-40]. As for the peak at $1369 \mathrm{~cm}^{-1}$ and $1383 \mathrm{~cm}-1$ observed in the spectrum of $\mathrm{ZnO}-80$ spectrum and $\mathrm{ZnO}-180$ spectrum respectively, it is due to the symmetrical stretching of the zinc carboxylate. As the size of the NPs increases, the content of the carboxylate $\left(\mathrm{COO}^{-}\right)$group in the samples decreased. [40].

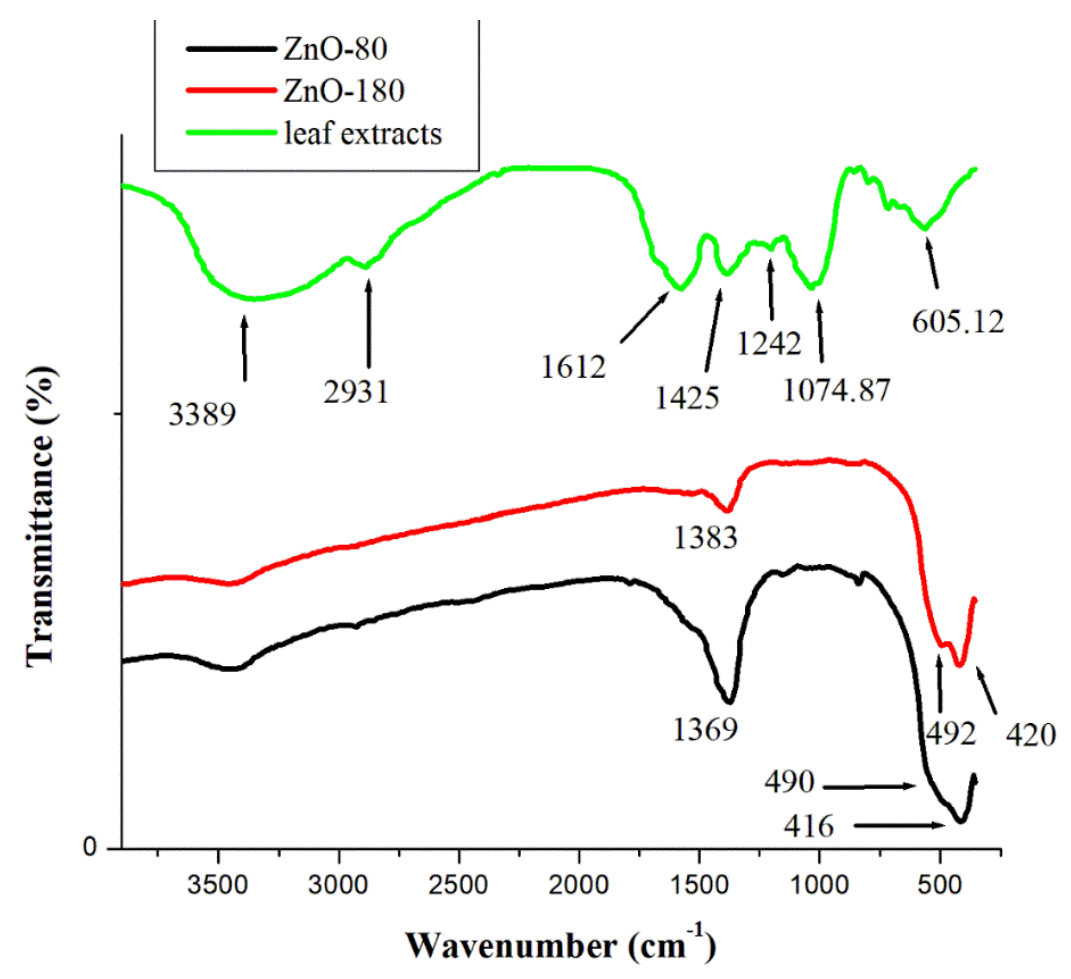

Figure 2. FTIR spectra of Rosmarinus officinalis leaf extract and $\mathrm{ZnO}$ NPs prepared at $80^{\circ} \mathrm{C}(\mathrm{ZnO}-80)$ and $180^{\circ} \mathrm{C}(\mathrm{ZnO}-180)$.

\subsubsection{XRD analysis}

The XRD patterns of bio-synthesized $\mathrm{ZnO}$ NPs from leaf extract of Rosmarinus officinalis for Zno-80 and ZnO-180 are shown in Figure 3. The sharp and narrow diffraction peaks indicate that the materials are well crystallized. The peaks found for $\mathrm{ZnO}-180$ correspond to Bragg reflections with $2 \theta$ values of $31.84^{\circ}, 34.48^{\circ}, 36.32^{\circ}, 47.62^{\circ}, 56.69^{\circ}, 62.95^{\circ}, 66.48$ 
${ }^{\circ}, 68.05^{\circ}, 69.18^{\circ} .72 .59^{\circ}$ and $77.07^{\circ}$. The peaks found for $\mathrm{ZnO}-80$ correspond to $31.74^{\circ}$, $34.39^{\circ}, 36.23^{\circ}, 47.54^{\circ}, 56.60^{\circ}, 62.85^{\circ}, 67.96^{\circ}, 66.40^{\circ}, 69.09^{\circ}, 72.51^{\circ}$ and $76.97^{\circ}$. The Xray diffraction patterns for both samples are in good agreement with the standard data of the hexagonal $\mathrm{ZnO}$ wurtzite structure (standard JCPDS card 36-1451). The reflections are attributed to the Miller-Bravais indices of (llll $\left.\begin{array}{lll}1 & 0\end{array}\right),\left(\begin{array}{lll}0 & 0 & 2\end{array}\right),\left(\begin{array}{lll}1 & 0 & 1\end{array}\right),\left(\begin{array}{lll}1 & 0 & 2\end{array}\right),\left(\begin{array}{lll}1 & 1 & 0\end{array}\right),\left(\begin{array}{lll}1 & 0 & 3\end{array}\right),\left(\begin{array}{l}2 \\ 2\end{array}\right.$ $\left.\begin{array}{l}0 \\ 0\end{array}\right),\left(\begin{array}{lll}1 & 1 & 2\end{array}\right),\left(\begin{array}{lll}2 & 0 & 1\end{array}\right),\left(\begin{array}{lll}0 & 0 & 4\end{array}\right)$ and (2 $\left.\begin{array}{lll}2 & 2\end{array}\right)$, planes of $\mathrm{ZnO}$ hexagonal phase structures, respectively, (standard JCPDS card 36-1451). The sharp and intense peaks indicate that the structures of the synthesized ZnO NPs were highly crystalline.

The average crystal size (D) of the particles was determined using Debye Scherer's formula, given below:

$$
D=\frac{0.94 \lambda}{\beta \cos \theta}
$$

where $D$ is the crystallite size, $\beta$ is the full width at half maximum, $\theta$ is the diffraction angle and $\lambda$ is the wavelength of $\mathrm{X}$-rays. The average crystallite size obtained for $\mathrm{ZnO}-80$ and $\mathrm{ZnO}-180$ was found to be 14.7 and $15.5 \mathrm{~nm}$ respectively.

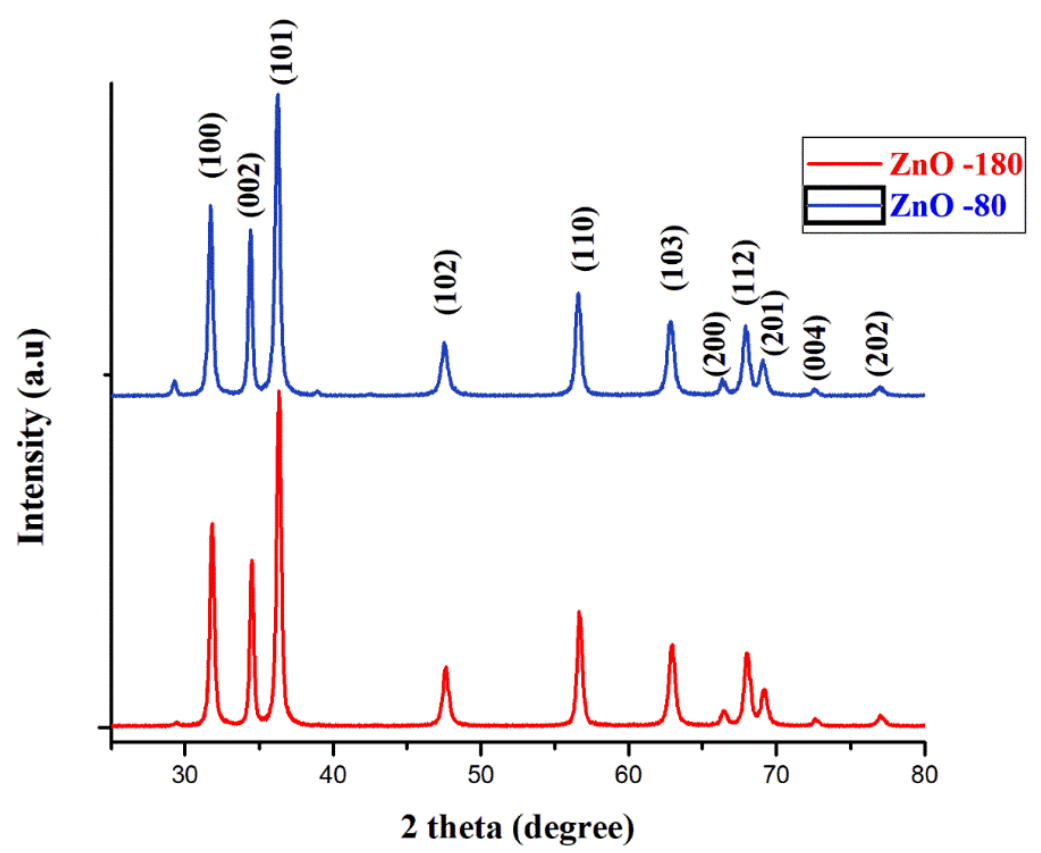

Figure 3. X-ray diffraction pattern of $\mathrm{ZnO}$ NPs prepared at $80^{\circ} \mathrm{C}(\mathrm{ZnO}-80)$ and $180^{\circ} \mathrm{C}$ ( $\mathrm{ZnO}-180)$. 


\subsubsection{TEM}

In order to see the effect of temperature on the texture of $\mathrm{ZnO}$ NPs synthesized using aqueous extract of Rosmarinus officinalis leaves, characterizations by TEM were carried out. The results of the analyzes illustrated in Figure 4 show that the particles synthesized at $80^{\circ} \mathrm{C}$ (ZnO-80) are mainly spherical with sizes varying from 18 to $40 \mathrm{~nm}$. However, some grains of larger sizes are also formed. On the other hand, NPs synthesized at $180^{\circ} \mathrm{C}(\mathrm{ZnO}-$ 180 ), they mainly have an elongated structure with sizes varying from 20 to $123 \mathrm{~nm}$. Some spherical particles of small sizes are also observed. The agglomerates were obtained by coalescing spherical NPs. These results are in agreement with those reported in the literature [41- 43]. Wasly et al. [41] studied the shape and size of the ZnO NPs synthesized at 100, $125,150,175$ and $200{ }^{\circ} \mathrm{C}$ by high resolution transmission electron microscopy (HR-TEM). The results showed that the synthesis temperature affects the shape and size of $\mathrm{ZnO}$ NPs. Spherical shaped particles were observed at $100^{\circ} \mathrm{C}$. With the increase in the reaction temperature, spherical and rod-shaped shapes of $\mathrm{ZnO}$ NPs were observed due to the increased growth rate. A further increase in temperature, almost all the ZnO NPs appeared in nanorod shaped clusters due to the fusion of smaller NPs and the formation of larger particles, that is, say clusters. Hassan Basri et al. [42] analyzed the structure of ZnO NPs synthesized at $28{ }^{\circ} \mathrm{C}$ and $60{ }^{\circ} \mathrm{C}$ by FESEM. NPs prepared at $28{ }^{\circ} \mathrm{C}$ clearly exhibited a mixture of spherical and rod-shaped particles, but better separated and less agglomerated compared to NPs prepared at $60{ }^{\circ} \mathrm{C}$, which agglomerated in the shape of a flower rod. In turn, these flower-shaped particles tend to stick together to form large clusters. Dutta et al. [43] They studied the effect of temperature on the aggregation of Au NPs in the temperature range of $20^{\circ} \mathrm{C}$ to $60{ }^{\circ} \mathrm{C}$ and found that the rate of aggregation increases with temperature. TEM measurements showed the formation of aggregate of Au NPs with different morphologies. The acceleration of the aggregation of NPs at higher temperatures can be explained by the decrease in the electrostatic repulsion force between NPs with increasing temperature [44-47]. It has been reported in other research work [47, 48], that the agglomerations could be due to a high surface energy of $\mathrm{ZnO}-\mathrm{NPs}$ resulting from a narrow space between the NPs which generally has been observed for synthesis carried out in aqueous medium. The increased rate of aggregation with temperature is similar to ordinary chemical reactions generally observed. At higher temperatures, the NPs come together to 
form nanoclusters, i.e. the average grain size increases with the annealing temperature and this was confirmed by XRD.
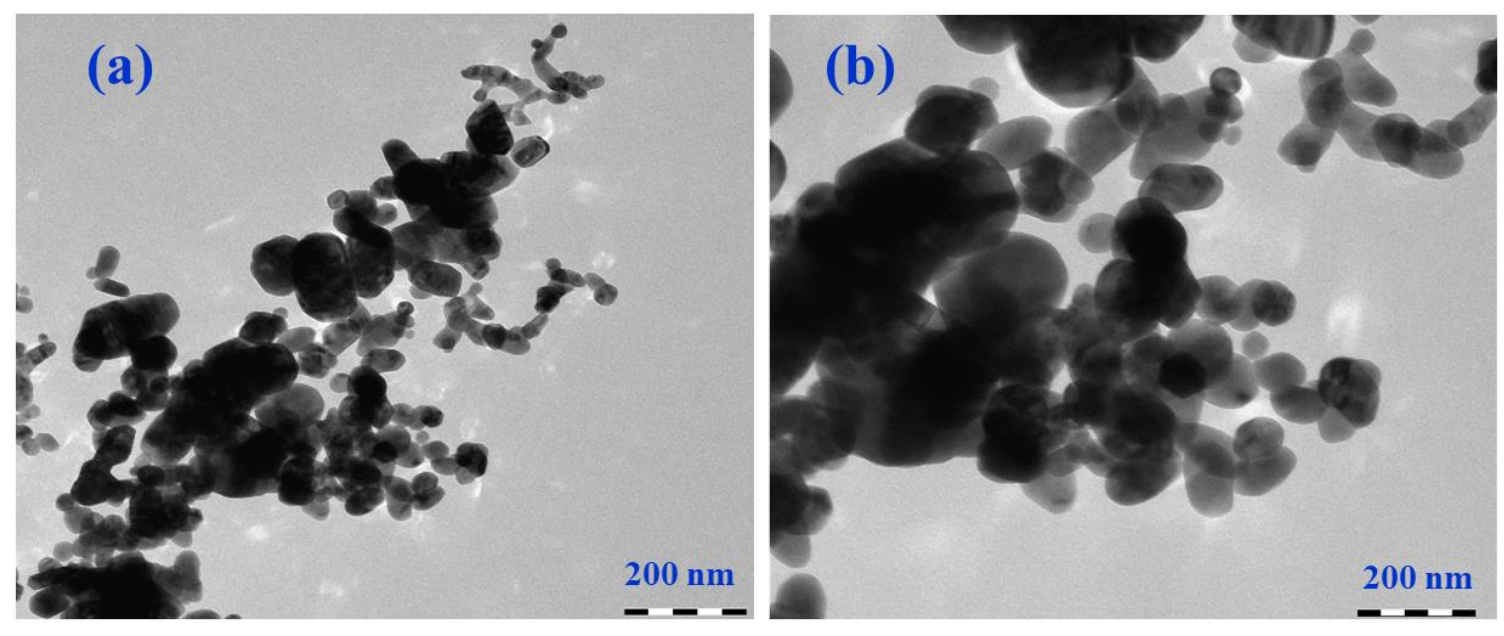

Figure 4. TEM images of: a) $\mathrm{ZnO}-80$ and b) $\mathrm{ZnO}-180$ prepared at $80^{\circ} \mathrm{C}$ and $180^{\circ} \mathrm{C}$ respectively and calcined at $500^{\circ} \mathrm{C}$.

\subsubsection{SEM with analysis}

Figure 5 shows the SEM morphology of $\mathrm{ZnO}-80$ and $\mathrm{ZnO}-180$ synthesized at $80{ }^{\circ} \mathrm{C}$ and $180{ }^{\circ} \mathrm{C}$ respectively. For the $\mathrm{ZnO}-80$ sample, the micrograph shows individual particles with irregular morphology and an agglomerated spherical particle. On the other hand, for the ZnO-180 sample, SEM imaging shows numerous flaky agglomerated spherical structures. It should be noted that for the two samples $\mathrm{ZnO}-80$ and $\mathrm{ZnO}-180$, the agglomerated particles exhibited pores, probably resulting from the escape of volatile substances or gases formed during calcination. Similar observations were reported in the literature $[49,50]$. 

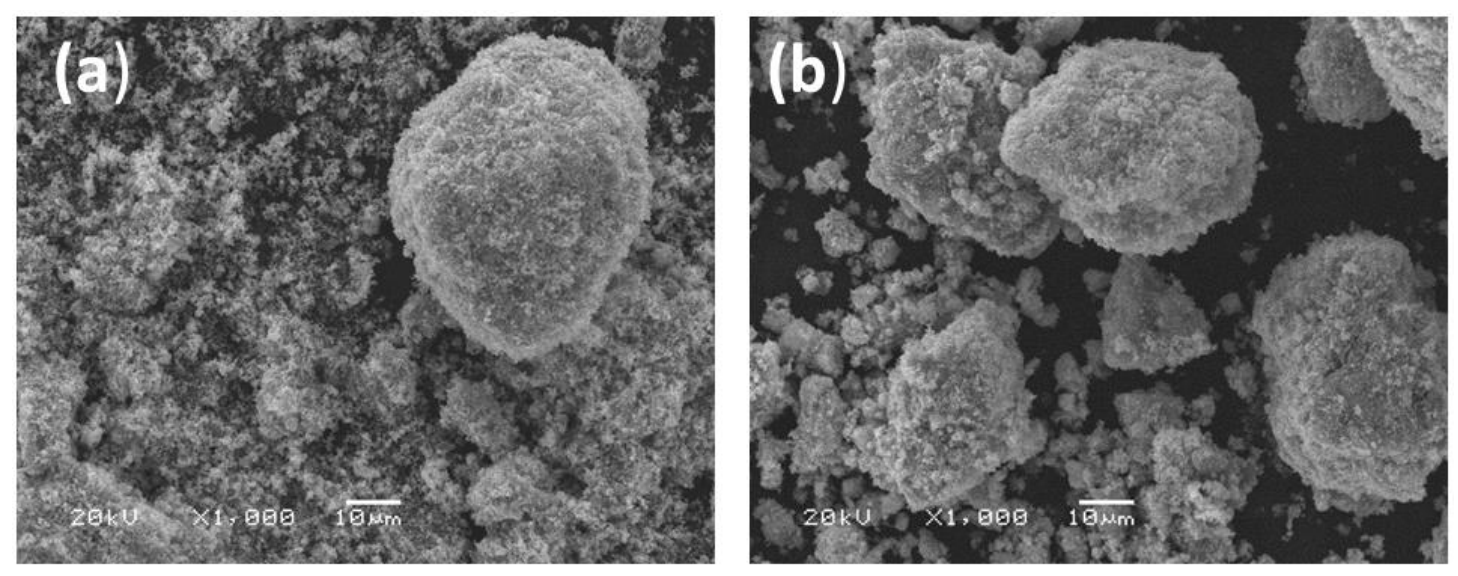

Figure 5. SEM images of: a) $\mathrm{ZnO}-80$ and b) $\mathrm{ZnO}-180$ prepared at $80^{\circ} \mathrm{C}$ and $180^{\circ} \mathrm{C}$ respectively and calcined at $500^{\circ} \mathrm{C}$.

\subsubsection{UV-visible analysis}

$\mathrm{UV}$-Vis spectroscopy was carried out to confirm the formation of the NPs of $\mathrm{ZnO}$ and to estimate the band gap value (Eg). The band gap energies of the samples were estimated using the Tauc equation :

$(\alpha \mathrm{h} v) 1 / 2=A(\mathrm{~h} v-E g)$

where the terms $h, v, \alpha$, and $E g$ represent Planck's constant, frequency, absorption coefficient, and band gap energy, respectively. A is a proportionality constant, and $n$ denotes the type of electron transition (for directly allowed transitions, $n=1 / 2$ ). As can be seen from $(\alpha \mathrm{h} v) 2$ versus energy plots (Figure 6), $\mathrm{ZnO}-80$ and $\mathrm{ZnO}-180$ have a bandgap value of 3.30 $\mathrm{eV}$ and $3.26 \mathrm{eV}$ respectively. The values of these band gaps are in the range of reported values of $\mathrm{ZnO}$ NPs [51, 52]. The bandgap of $\mathrm{ZnO}-80$ material is slightly higher than that of $\mathrm{ZnO}-180$. This could be due to the difference in the size of their NPs. It is well known that the variation in band gap can be due to a structural parameter and to the size of the grains. In fact, a strong correlation between absorption peak and particle size has been observed [53]. Therefore, this result indicates that the crystal particle size of $\mathrm{ZnO}-80$ is smaller than that of $\mathrm{ZnO}-180$, which is in agreement with those of XRD and TEM analyzes. 


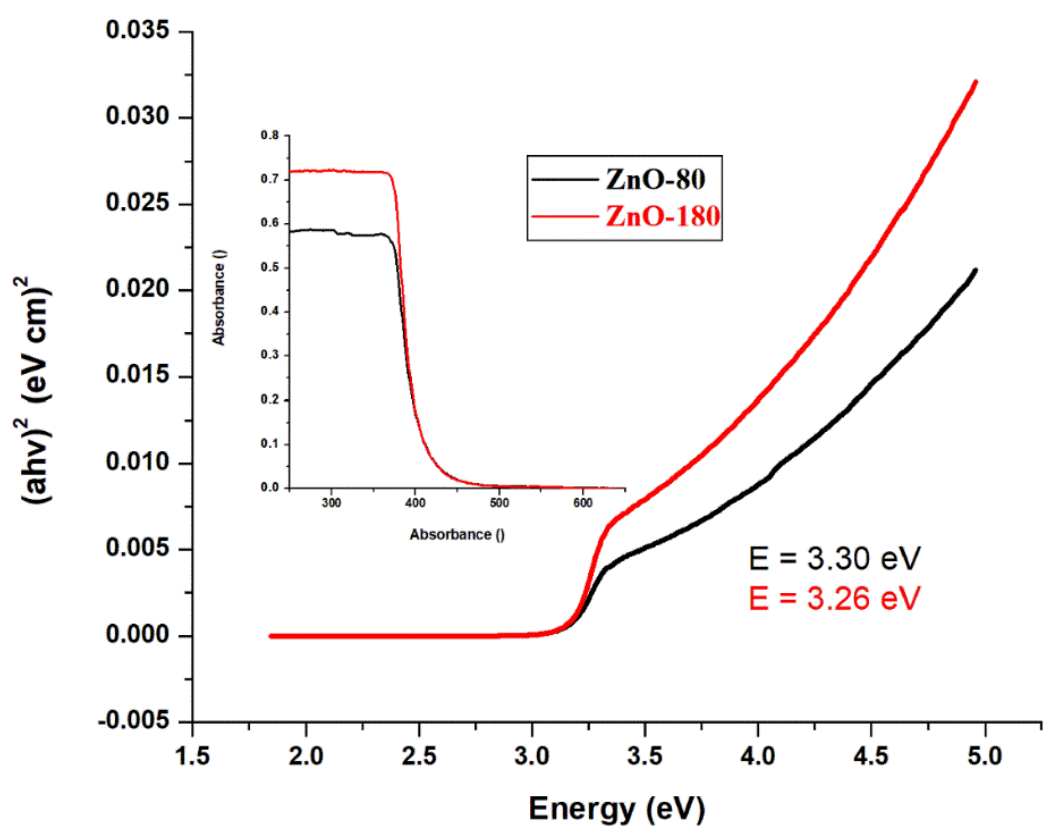

Figure 6. UV spectrum and band gab for a) $\mathrm{ZnO}-80$ and b) $\mathrm{ZnO}-180$ prepared at $80^{\circ} \mathrm{C}$ and $180^{\circ} \mathrm{C}$ respectively and calcined at $500^{\circ} \mathrm{C}$.

\subsubsection{Thermogravimetric Analysis}

TGA performed in $25{ }^{\circ} \mathrm{C}-1000{ }^{\circ} \mathrm{C}$ at a constant heating rate of $10{ }^{\circ} \mathrm{C} /$ minute under air atmosphere. The thermograms of both metal oxide NPs are shown in Figure 7. As can be seen, the thermogravimetric (TG) curve for both samples shows three stages of weight loss. The first stage indicates a weight loss of $1.4 \%$ and $1.3 \%$ for $\mathrm{ZnO}-80$ and $\mathrm{ZnO}-180$ respectively was observed at around $140{ }^{\circ} \mathrm{C}$ due to water evaporation. A second weight loss of $1.7 \%$ and $1.2 \%$ for $\mathrm{ZnO}-80$ and $\mathrm{ZnO}-180$ respectively appeared while temperature increases at $140-260{ }^{\circ} \mathrm{C}$ that could be attributed to the decomposition of the bio entities from the extract capped on the synthesized zinc oxide NPs. This thermal decomposition can be yet another confirmation for the presence of phytoconstituents that are functionalized on the NPs. Similar results of thermal decomposition of phytochemicals coated on the NPs have been reported [54]. A third weight loss of $5.9 \%$ and $1.9 \%$ respectively appeared while temperature increases at $260-900^{\circ} \mathrm{C}$ which, probably was due to the thermal degradation of less volatile aromatic compounds [55]. It should be noted that beyond $220^{\circ} \mathrm{C}$ the weight loss for $\mathrm{ZnO}-180$ becomes greater than that observed for $\mathrm{ZnO}-80$. This is consistent with the 
results of SEM which shows that $\mathrm{ZnO}-180$ exhibits more agglomerations which may be organic compounds coating the $\mathrm{ZnO}$ NPs.

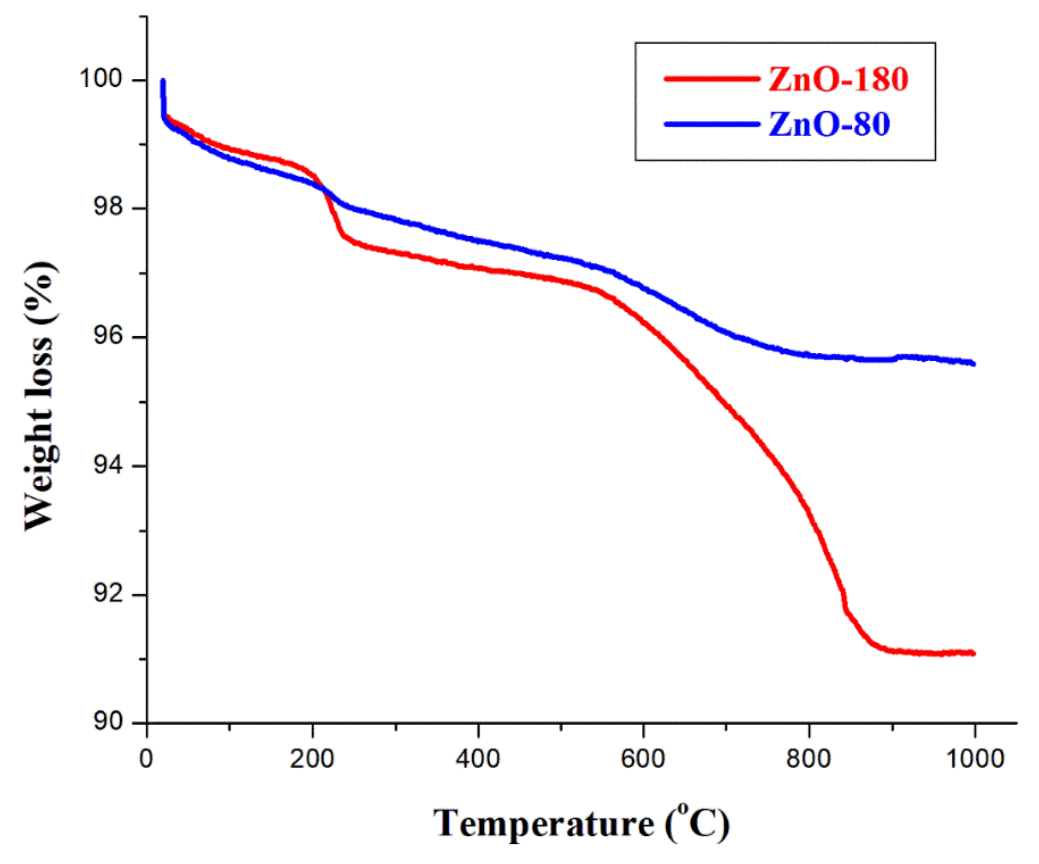

Figure 7. Thermograph of: a) $\mathrm{ZnO}-80$ and b) $\mathrm{ZnO}-180$ prepared at $80^{\circ} \mathrm{C}$ and $180^{\circ} \mathrm{C}$ respectively and calcined at $500^{\circ} \mathrm{C}$.

\section{Mechanism for the formation of $\mathrm{ZnO}$}

To establish a possible mechanism for the formation of $\mathrm{ZnO}$ NPs involving one of the substances present in the plant extract, it is first necessary to verify the formation of the NPs after addition of the extract. To do this, the $\mathrm{ZnO}-80$ particles formed after the action of the substance but before calcination were analyzed by UV-Visible spectroscopy. By way of comparison, the characterization of the $\mathrm{ZnO}-80$ particles after calcination was also carried out. The analysis was performed under aqueous conditions in the wavelength range from $250 \mathrm{~nm}$ to $550 \mathrm{~nm}$ and the results are presented in Figure 8. The absorption peaks observed at 371 and $382 \mathrm{~nm}$ for Zno-80 before and after calcination respectively confirms the formation of $\mathrm{ZnO}$ NPs. Similar results of absorption band were also observed by various researchers [56-58]. The absorption peaks observed at 371 and $382 \mathrm{~nm}$ are due to the 
intrinsic band gap of $\mathrm{Zn}-\mathrm{O}$ absorption. As for the substance probably involved in the synthesis of $\mathrm{ZnO}-80 \mathrm{NPs}$, the results of FTIR (Figure 2), showed that carboxylate species remained adsorbed on the NPs even after calcination. It is therefore probable that these species are involved in the formation of NPs. It should be noted that various leaf extracts contain substances which can act as reducing and capping agent, thus preventing aggregation of NPs. Indeed, it has been observed that the action of certain biological compounds leads to the reduction of $\mathrm{Zn}^{2+}$ to $\mathrm{ZnO}$ NPs [59]. It has also been observed that proteins and functional groups (carboxylates) are involved in the reduction of gold NPs [60]. On the other hand, it has been shown that when a zinc oxide powder is dispersed in distilled water in the $\mathrm{pH}$ range 7-9, it is in equilibrium with various species in aqueous solution and that is the species $\mathrm{Zn}^{2+}$ and $\mathrm{Zn}(\mathrm{OH})^{+}$which are the predominant [61]. It is therefore probable that the formation of $\mathrm{ZnO}$ NPs goes through the formation of $\mathrm{Zn}(\mathrm{OH})^{+}$. Based on the above results, a mechanism (Figure 9) has been proposed.

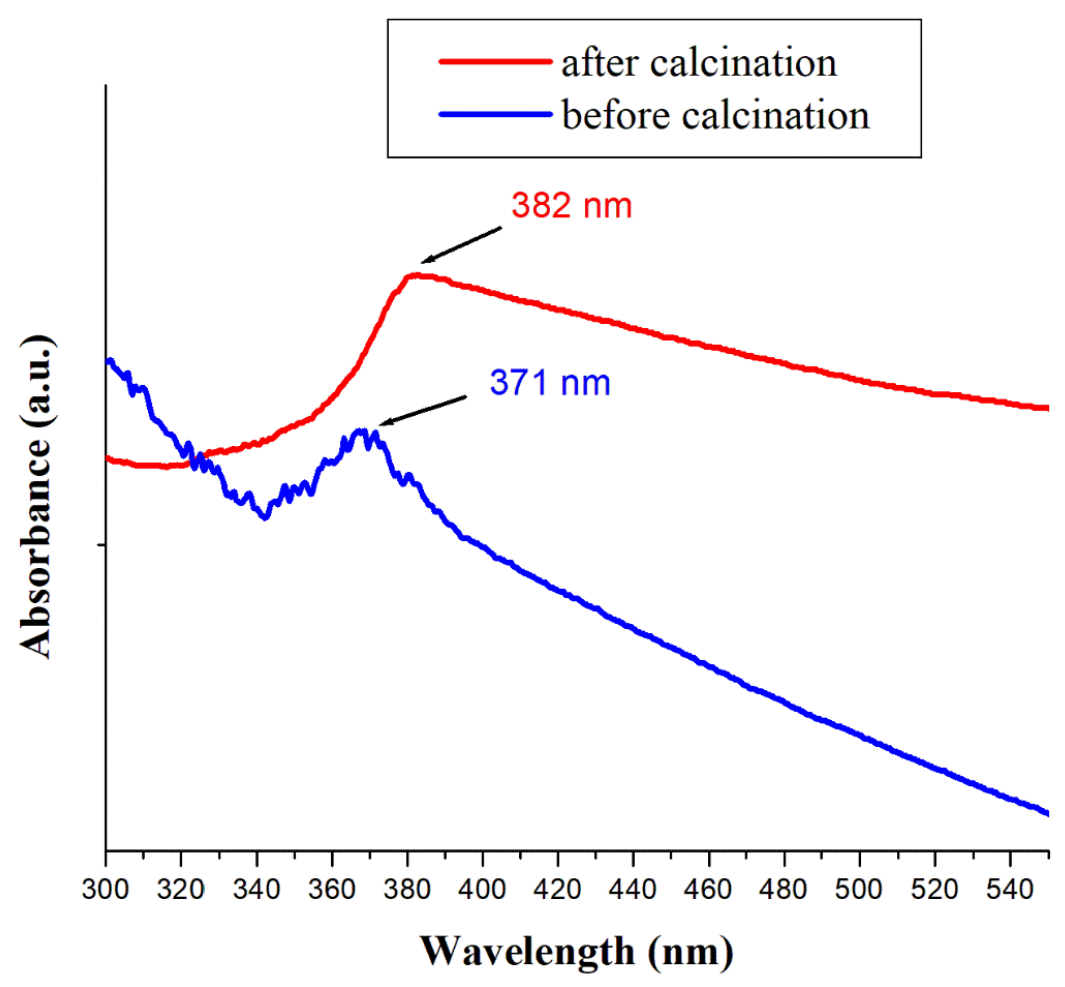

Figure 8. UV spectrum of $\mathrm{ZnO}-80$ : a) before calcination and b) after calcination 


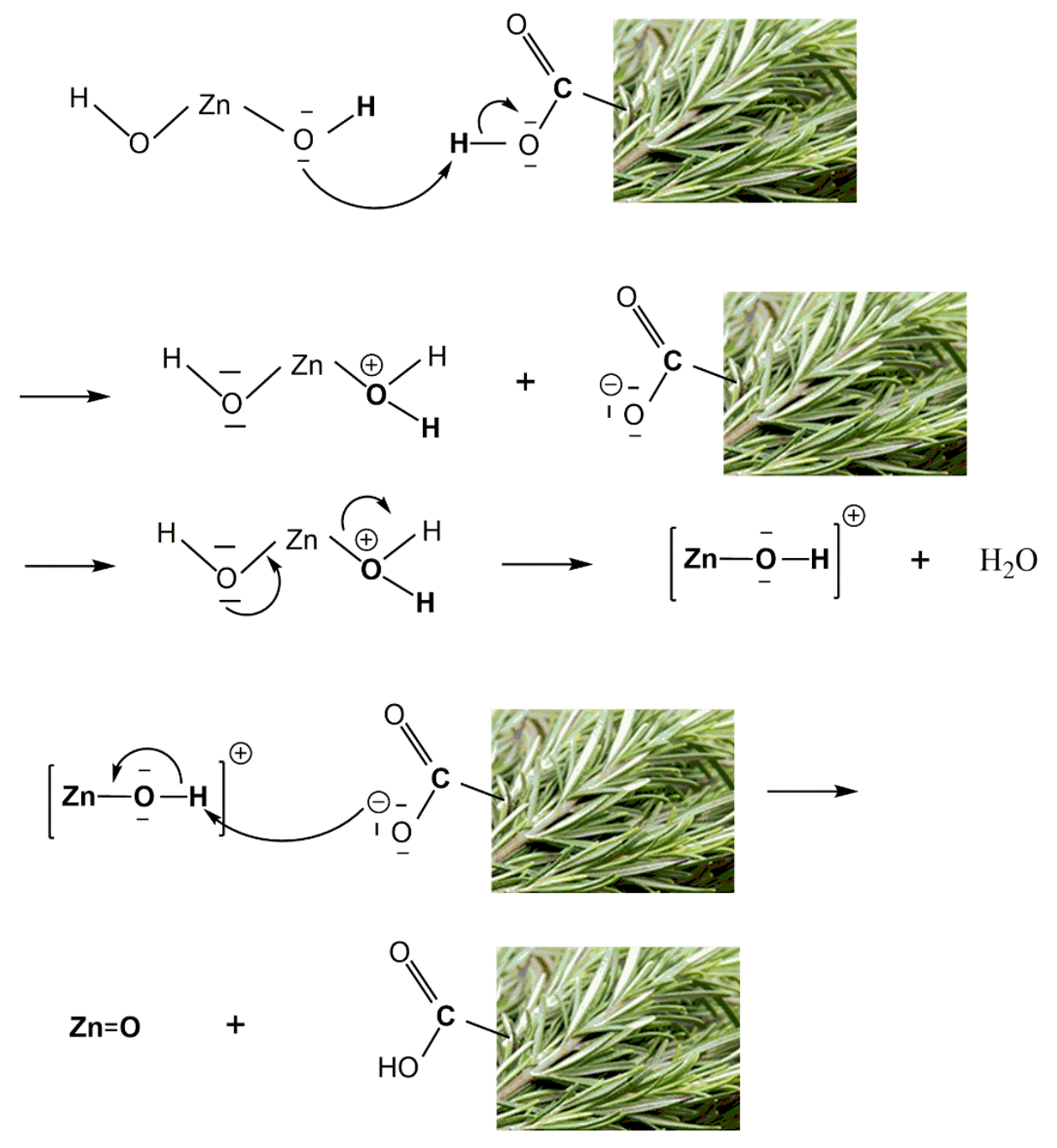

Figure 9. Possible reaction mechanism for the formation of $\mathrm{ZnO}$ NPs in presence of carboxyl group (-COOH) of Rosmarinus officinalis leaf extract.

\subsection{Photocatalytic activity}

The photocatalytic activities of the synthesized $\mathrm{ZnO}$ NPs were evaluated via the photodegradation of methylene blue (MB) and $\mathrm{CV}$ under sunlight irradiation. Prior to illumination, $10 \mathrm{mg}$ photocatalyst was added to the dye aqueous solution (10 mL, 10ppm). The solution was stirred in the dark for 20 minutes in order to achieve absorption-desorption equilibrium, then the photocatalytic reaction was started. The photocatalyst will then be exposed to the sunlight for the desired time at $40^{\circ} \mathrm{C}$. Figure 10 shows the UV-Vis absorption spectra of $\mathrm{MB}$ and $\mathrm{CV}$ absorbance with respect to time for $\mathrm{ZnO}-80$ and $\mathrm{ZnO}-180$. The 
aqueous solution of the MB molecules exhibits two peaks, one at 664 and the other at 615 $\mathrm{nm}$, which correspond respectively to monomers and dimers. [62]. Upon irradiation, the peak at $664 \mathrm{~nm}$ has a progressively blue shift to shorter wavelength (Figure 10 (a)) because of hypsochromic effect $[63,64]$. In the presence of $\mathrm{ZnO}-80$ the absorbance of MB decreased sharply after $30 \mathrm{~min}$. Initially, the absorption peak at $664 \mathrm{~nm}$ was much larger than the absorption peak at $615 \mathrm{~nm}$ which gives a big difference between their intensities. After 30 min, this difference is attenuated, thus indicating that the rate of degradation of the monomers is much higher than that of the dimers [65]. In addition to the decrease in the intensities of the two peaks, a slight shift towards the blue of the bands located at $664 \mathrm{~nm}$ also observed. This is caused by the $\mathrm{N}$-demethylated degradation concomitant with the degradation of phenothiazine [66].

The influence of the irradiation time on the discoloration of the CV (Figure 10 (b)) was followed by the characteristic peak at $590 \mathrm{~nm}$, corresponding to the conjugated triphenylmethane chromophore. The decrease in absorbance at $590 \mathrm{~nm}$ with irradiation is due to the degradation of the chromophore responsible for the characteristic color of the CV. The hypochromic shift of the peak at $590 \mathrm{~nm}$ of the chromophore at about $575 \mathrm{~nm}$ indicates an $\mathrm{N}$-dimethylation reaction [67] leading to $\mathrm{NO}_{3}^{-}$ions $[68,69]$. 

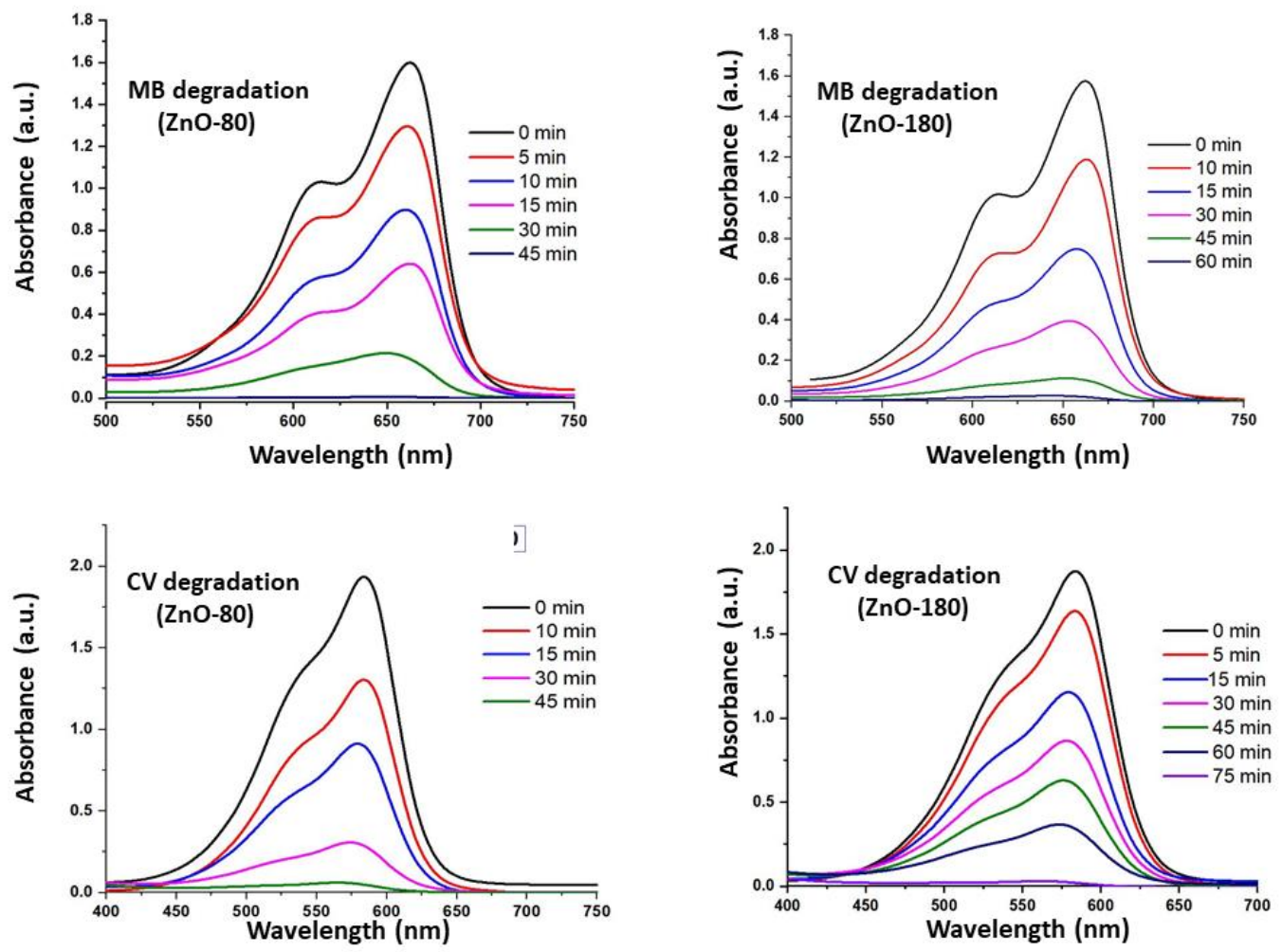

Figure 10. UV-Vis absorption spectra of degradation of $\mathrm{MB}$ and $\mathrm{CV}$ by $\mathrm{ZnO}-80$ and $\mathrm{ZnO}-180$ under sunlight irradiation. Reaction conditions: Dye concentration 10 $\mathrm{mg}$ of photocatalyst and $10 \mathrm{ml}$ of $10 \mathrm{ppm}$ of dyes.

Figure 11 shows the decreasing concentration of $\mathrm{MB}$ and $\mathrm{CV}$ with respect to time for $\mathrm{ZnO}$ 80 and $\mathrm{ZnO}-180$. As shown in Figure 9(a) MB was degraded completely after irradiating $45 \mathrm{~min}$ and $60 \mathrm{~min}$ by $\mathrm{ZnO}-80$ and $\mathrm{ZnO}-180$, respectively. Whereas, the complete degradation of $\mathrm{CV}$ takes 60 and $75 \mathrm{~min}$ for $\mathrm{ZnO}-80$ and $\mathrm{ZnO}-180$ respectively. The higher $\mathrm{MB}$ and $\mathrm{CV}$ degradation rate over $\mathrm{ZnO}-80$ proves its better performance compared to $\mathrm{ZnO}$ 180. These results are consistent with the texture properties of the prepared $\mathrm{ZnO}-80$ and $\mathrm{ZnO}-180$ photocatalysts (Table 1). It can be seen that $\mathrm{ZnO}-80$ presents lower crystallite size, higher surface area and higher pore volume than $\mathrm{ZnO}-180$. 

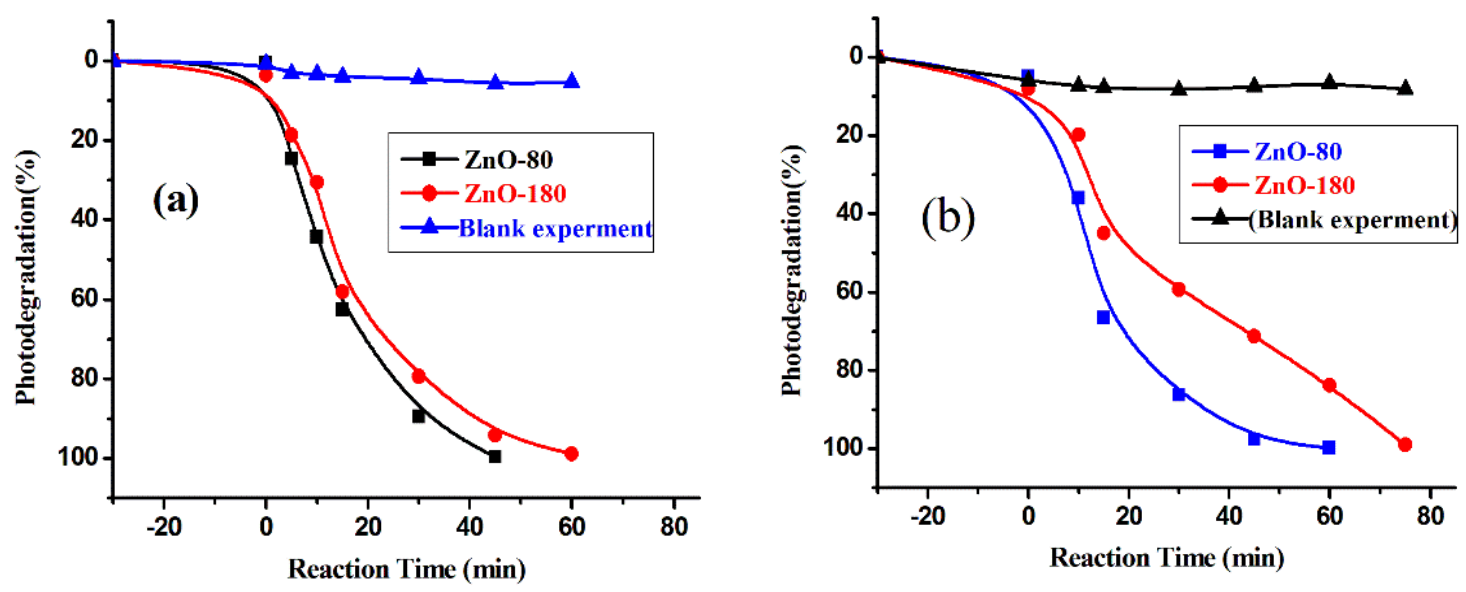

Figure 11. Effect of $\mathrm{ZnO}-80$ and $\mathrm{ZnO}-180$ on the photocatalytic degradation of (a) $\mathrm{MB}$, (b) CV under sunlight irradiation. Reaction conditions: Dye concentration $10 \mathrm{mg}$ of photocatalyst and $10 \mathrm{ml}$ of $10 \mathrm{ppm}$ of dyes

Table 1. Texture properties of the $\mathrm{ZnO}-80$ and $\mathrm{ZnO}-180$ metal oxide NPs.

\begin{tabular}{lll}
\hline Physical properties & $\mathrm{ZnO}-80$ & $\mathrm{ZnO}-180$ \\
\hline BET Surface Area $\left(\mathrm{m}^{2} / \mathrm{g}\right)$ & 11.9958 & 8.6474 \\
Pore Volume $\left(\mathrm{cm}^{3} / \mathrm{g}\right)$ & 0.236241 & 0.121089 \\
Total Area in Pore $\left(\mathrm{m}^{2} / \mathrm{g}\right)$ & 7.409 & 5.137 \\
Crystallite size $(\mathrm{nm})$ & 14.7 & 15.5 \\
Pore Size $(\AA)$ & 787.7445 & 560.1170 \\
\hline
\end{tabular}

\subsection{Reusability}

In order to examine the reusability of the biosynthesized $\mathrm{ZnO}-80$ and $\mathrm{ZnO}-180$ photocatalysts, we tested them after use to see the stability of their photocatalytic activity. Both solids were tested under the same conditions as those in which they gave complete degradation of $\mathrm{MB}$ and $\mathrm{CV}$, ie $100 \%$. The results obtained (Table 2) show that $\mathrm{ZnO}-80$ degrades $\mathrm{MB}$ by $96.7 \%$ while $\mathrm{ZnO}-180$ degrades it by $93.8 \%$. As for the discoloration of the $\mathrm{CV}$, the results obtained show that the two samples, $\mathrm{ZnO}-80$ and $\mathrm{ZnO}-180$, discolored it to $95.1 \%$. A slight decrease in activity therefore occurred. This is expected because a decrease in photocatalytic activity after reuse of the catalyst has been observed by many researchers $[70,71]$. This slight decrease in degradation is acceptable and allows reuse of these catalysts. 
Table .2 Reusability of $\mathrm{ZnO}-80$ and $\mathrm{ZnO}-180$ photocatalysts for the degradation of $\mathrm{MB}$ and CV dyes. Reaction conditions: Dye concentration $10 \mathrm{mg}$ of photocatalyst and $10 \mathrm{ml}$ of 10 ppm of dyes.

\begin{tabular}{cllll}
\hline Dye & \multicolumn{2}{c}{ ZnO-80 } & \multicolumn{2}{c}{ ZnO-180 } \\
\hline & Fresh & Used & Fresh & Used \\
$\mathrm{MB}$ & 100 & 96.7 & 100 & 93.8 \\
$\mathrm{CV}$ & 100 & 95.1 & 100 & 95.1 \\
\hline
\end{tabular}

\section{Conclusion}

In the present study, the degradation of methylene blue and crystal violet dyes by $\mathrm{ZnO}$ NPs under sunlight irradiation was investigated. ZnO NPs were synthesized using Rosmarinus officinalis leaf extract at $80^{\circ} \mathrm{C}(\mathrm{ZnO}-80)$ and $180^{\circ} \mathrm{C}(\mathrm{ZnO}-180)$.

The FTIR spectra of the synthesized bio ZnO NPs showed the presence of the carboxylate group $\left(\mathrm{COO}^{-}\right)$adsorbed on the NPs of the two samples. It is therefore probable that these species are involved in the formation of NPs. Based on these results, a mechanism has been proposed. The XRD, TEM and SEM results showed that the synthesis temperature affects the shape and size of $\mathrm{ZnO}$ NPs. A lower temperature leads to the production of smaller, spherical shaped and less agglomerated particles.

Photocatalytic tests revealed that $\mathrm{ZnO}-80$ NPs were more efficient in photodegradation of $\mathrm{MB}$ and $\mathrm{CV}$ dyes compared to $\mathrm{ZnO}-180$. The high activity of $\mathrm{ZnO}-80$ was due to better physicochemical properties compared to $\mathrm{ZnO}-180$.

$\mathrm{ZnO}-80$ which was prepared by a cheap and easy procedure compared to $\mathrm{ZnO}-180$, which was prepared by usual method using autoclave and high temperature, effectively degrades MB and CV dyes under sunlight.

Photo-degradation of dyes under sunlight as an abundantly available energy source by $\mathrm{ZnO}$, prepared by a simple method, can be exploited to develop an environmentally friendly and economical process. 
Author Contributions: Tahani Al-Garni provided materials and performed characterizations, Naaser A.Y. Abduh performed the experiments and analyzed the experimental data, Abdullah Al Kahtani provided materials and funding, Ahmed Aouissi designed and wrote the article. All authors have read and accepted the published version of the manuscript.

Acknowledgements: The authors extended their appreciation to the Deanship of Scientific Research at King Saud University: [Grant Number RG-1441-507].

Conflicts of Interest: The authors declare no conflicts of interest.

\section{References}

1. Amini, M.; Ashrafi, M. Photocatalytic degradation of some organic dyes under solar light irradiation using TiO2 and ZnO NPs. Nanochemistry Research 2016, 1, 79-86.

2. Muhd Julkapli, N.; Bagheri, S.; Bee Abd Hamid, S. Recent advances in heterogeneous photocatalytic decolorization of synthetic dyes. The Scientific World Journal 2014, 2014.

3. Bremner, D.H.; Molina, R.; Martínez, F.; Melero, J.A.; Segura, Y. Degradation of phenolic aqueous solutions by high frequency sono-Fenton systems (US-Fe2O3/SBA-15H2O2). Applied Catalysis B: Environmental 2009, 90, 380-388.

4. Amini, M.; Pourbadiei, B.; Ruberu, T.P.A.; Woo, L.K. Catalytic activity of MnO x/WO 3 NPs: synthesis, structure characterization and oxidative degradation of methylene blue. New journal of chemistry 2014, 38, 1250-1255.

5. Mani, S.; Bharagava, R.N. Exposure to crystal violet, its toxic, genotoxic and carcinogenic effects on environment and its degradation and detoxification for environmental safety. Reviews of Environmental Contamination and Toxicology Volume 237 2016, 71-104.

6. El Khomri, M.; El Messaoudi, N.; Dbik, A.; Bentahar, S.; Lacherai, A. Efficient adsorbent derived from Argania Spinosa for the adsorption of cationic dye: Kinetics, mechanism, isotherm and thermodynamic study. Surfaces and Interfaces 2020, 20, 100601.

7. Ishaq, M.; Javed, F.; Amad, I.; Ullah, H.; Hadi, F.; Sultan, S. Adsorption of crystal violet dye from aqueous solutions onto low-cost untreated and $\mathrm{NaOH}$ treated almond shell. Iranian Journal of Chemistry and Chemical Engineering (IJCCE) 2016, 35, 97-106. 
8. Ali, N.; Bilal, M.; Khan, A.; Ali, F.; Iqbal, H.M. Effective exploitation of anionic, nonionic, and nanoparticle-stabilized surfactant foams for petroleum hydrocarbon contaminated soil remediation. Science of the Total Environment 2020, 704, 135391.

9. Ahmad, I.; Khan, S.B.; Kamal, T.; Asiri, A.M. Visible light activated degradation of organic pollutants using zinc-iron selenide. Journal of Molecular Liquids 2017, 229, 429435.

10. Fayoud, N.; Younssi, S.A.; Tahiri, S.; Albizane, A. Etude cinétique et thermodynamique de l'adsorption de bleu de méthylène sur les cendres de bois (Kinetic and thermodynamic study of the adsorption of methylene blue on wood ashes). J. Mater. Environ. Sci 2015, 6, 3295-3306.

11. Shakoor, S.; Nasar, A. Removal of methylene blue dye from artificially contaminated water using citrus limetta peel waste as a very low cost adsorbent. Journal of the Taiwan Institute of Chemical Engineers 2016, 66, 154-163.

12. Fazli, M.M.; Mesdaghinia, A.; Naddafi, K.; Nasseri, S.; Yunesian, M.; Assadi, M.M.; Rezaie, S.; Hamzehei, H. Optimization of reactive blue 19 decolorization by ganoderma sp. using response surface methodology. Journal of Environmental Health Science \& Engineering 2010, 7, 35-42.

13. Hussain, S.; Ullah, Z.; Gul, S.; Khattak, R.; Kazmi, N.; Rehman, F.; Khan, S.; Ahmad, K.; Imad, M.; Khan, A. Adsorption characteristics of magnesium-modified bentonite clay with respect to acid blue 129 in aqueous media. Polish Journal of Environmental Studies 2016, 25, 1947-1953.

14. Wahid, F.; Mohammadzai, I.U.; Khan, A.; Shah, Z.; Hassan, W.; Ali, N. Removal of toxic metals with activated carbon prepared from Salvadora persica. Arabian Journal of Chemistry 2017, 10, S2205-S2212.

15. Klingenberg, M.; Becker, J.; Eberth, S.; Kube, D.; Wilting, J. The NADPH oxidase inhibitor imipramine-blue in the treatment of Burkitt lymphoma. Molecular cancer therapeutics 2014, 13, 833-841.

16. Zargar, B.; Parham, H.; Hatamie, A. Fast removal and recovery of amaranth by modified iron oxide magnetic NPs. Chemosphere 2009, 76, 554-557.

17. Xu, A.; Li, X.; Ye, S.; Yin, G.; Zeng, Q. Catalyzed oxidative degradation of methylene blue by in situ generated cobalt (II)-bicarbonate complexes with hydrogen peroxide. Applied Catalysis B: Environmental 2011, 102, 37-43. 
18. Anjaneyulu, Y.; Chary, N.S.; Raj, D.S.S. Decolourization of industrial effluents-available methods and emerging technologies-a review. Reviews in Environmental Science and Bio/Technology 2005, 4, 245-273.

19. Hernández-Ramírez, A.; Medina-Ramírez, I. Photocatalytic semiconductors; Springer: 2016.

20. Shinde, S.; Shinde, P.; Bhosale, C.; Rajpure, K. Zinc oxide mediated heterogeneous photocatalytic degradation of organic species under solar radiation. Journal of Photochemistry and Photobiology B: Biology 2011, 104, 425-433.

21. Chang, X.; Li, Z.; Zhai, X.; Sun, S.; Gu, D.; Dong, L.; Yin, Y.; Zhu, Y. Efficient synthesis of sunlight-driven $\mathrm{ZnO}$-based heterogeneous photocatalysts. Materials \& Design 2016, 98 , 324-332.

22. Kou, J.; Lu, C.; Wang, J.; Chen, Y.; Xu, Z.; Varma, R.S. Selectivity enhancement in heterogeneous photocatalytic transformations. Chemical reviews 2017, 117, 1445-1514.

23. Qu, X.; Alvarez, P.J.; Li, Q. Applications of nanotechnology in water and wastewater treatment. Water research 2013, 47, 3931-3946.

24. Bao, J.; Zimmler, M.A.; Capasso, F.; Wang, X.; Ren, Z. Broadband ZnO single-nanowire light-emitting diode. Nano letters 2006, 6, 1719-1722.

25. Mahadik, M.; Shinde, S.; Kumbhar, S.; Pathan, H.; Rajpure, K.; Bhosale, C. Enhanced photocatalytic activity of sprayed Au doped ferric oxide thin films for salicylic acid degradation in aqueous medium. Journal of Photochemistry and Photobiology B: Biology 2015, 142, 43-50.

26. Wang, A.-n.; Teng, Y.; Hu, X.-f.; Wu, L.-h.; Huang, Y.-j.; Luo, Y.-m.; Christie, P. Diphenylarsinic acid contaminated soil remediation by titanium dioxide (P25) photocatalysis: Degradation pathway, optimization of operating parameters and effects of soil properties. Science of the Total Environment 2016, 541, 348-355.

27. Choi, K.; Kang, T.; Oh, S.-G. Preparation of disk shaped $\mathrm{ZnO}$ particles using surfactant and their PL properties. Materials Letters 2012, 75, 240-243.

28. Al-Fori, M.; Dobretsov, S.; Myint, M.T.Z.; Dutta, J. Antifouling properties of zinc oxide nanorod coatings. Biofouling 2014, 30, 871-882.

29. Yogendra, K.; Naik, S.; Mahadevan, K.; Madhusudhana, N. A comparative study of photocatalytic activities of two different synthesized $\mathrm{ZnO}$ composites against Coralene Red F3BS dye in presence of natural solar light. International Journal of Environmental Sciences and Research 2011, 1, 11-15. 
30. Zhang, X.; Zhou, G.; Zhang, H.; Wu, C.; Song, H. Characterization and activity of visible light-driven $\mathrm{TiO} 2$ photocatalysts co-doped with nitrogen and lanthanum. Transition Metal Chemistry 2011, 36, 217-222.

31. Ahmed, S.; Saifullah; Ahmad, M.; Swami, B.L.; Ikram, S. Green synthesis of silver NPs using Azadirachta indica aqueous leaf extract. Journal of radiation research and applied sciences 2016, 9, 1-7.

32. Lateef, A.; Akande, M.A.; Ojo, S.A.; Folarin, B.I.; Gueguim-Kana, E.B.; Beukes, L.S. Paper wasp nest-mediated biosynthesis of silver NPs for antimicrobial, catalytic, anticoagulant, and thrombolytic applications. 3 Biotech 2016, 6, 1-10.

33. Goudarzi, M.; Mir, N.; Mousavi-Kamazani, M.; Bagheri, S.; Salavati-Niasari, M. Biosynthesis and characterization of silver NPs prepared from two novel natural precursors by facile thermal decomposition methods. Scientific reports 2016, 6, 1-13.

34. Szymanska-Chargot, M.; Zdunek, A. Use of FT-IR spectra and PCA to the bulk characterization of cell wall residues of fruits and vegetables along a fraction process. Food biophysics 2013, 8, 29-42.

35. Mohammad, G.R.K.S.; Tabrizi, M.H.; Ardalan, T.; Yadamani, S.; Safavi, E. Green synthesis of zinc oxide NPs and evaluation of anti-angiogenesis, anti-inflammatory and cytotoxicity properties. Journal of biosciences 2019, 44, 1-9.

36. Khatami, M.; Mehnipor, R.; Poor, M.H.S.; Jouzani, G.S. Facile biosynthesis of silver NPs using Descurainia sophia and evaluation of their antibacterial and antifungal properties. Journal of Cluster Science 2016, 27, 1601-1612.

37. Sharma, S.; Kumar, S.; Bulchandini, B.; Taneja, S.; Banyal, S. Green synthesis of silver NPs and their antimicrobial activity against gram positive and gram negative bacteria. Int. J. Biotechnol. Bioeng. Res 2013, 4, 711-714.

38. Rehman, H.; Ali, Z.; Hussain, M.; Gilani, S.; Shahzady, T.; Zahra, A.; Hussain, S.; Hussain, H.; Hussain, I.; Farooq, M. Synthesis and characterization of ZnO NPs and their use as an adsorbent for the arsenic removal from drinking water. Digest Journal of Nanomaterials and Biostructures 2019, 14, 1033-1040.

39. Xiong, G.; Pal, U.; Serrano, J.; Ucer, K.; Williams, R. Photoluminesence and FTIR study of ZnO NPs: the impurity and defect perspective. physica status solidi c 2006, 3, 35773581 .

40. Wasly, H.; Abd El-Sadek, M.; Henini, M. Influence of reaction time and synthesis temperature on the physical properties of $\mathrm{ZnO}$ NPs synthesized by the hydrothermal method. Applied Physics A 2018, 124, 76. 
41. Hassan Basri, H.; Talib, R.A.; Sukor, R.; Othman, S.H.; Ariffin, H. Effect of synthesis temperature on the size of $\mathrm{ZnO}$ NPs derived from pineapple peel extract and antibacterial activity of ZnO-starch nanocomposite films. Nanomaterials 2020, 10, 1061.

42. Dutta, A.; Paul, A.; Chattopadhyay, A. The effect of temperature on the aggregation kinetics of partially bare gold NPs. RSC advances 2016, 6, 82138-82149.

43. Chen, Y.; Huang, Y.; Li, K. Temperature effect on the aggregation kinetics of CeO2 NPs in monovalent and divalent electrolytes. J. Environ. Anal. Toxicol 2012, 2, 158-162.

44. Li, K.; Zhang, W.; Huang, Y.; Chen, Y. Aggregation kinetics of $\mathrm{CeO} 2 \mathrm{NPs}$ in $\mathrm{KCl}$ and $\mathrm{CaCl} 2$ solutions: measurements and modeling. Journal of Nanoparticle Research 2011, 13, 6483-6491.

45. Li, K.; Chen, Y. Effect of natural organic matter on the aggregation kinetics of CeO2 NPs in $\mathrm{KCl}$ and $\mathrm{CaCl} 2$ solutions: measurements and modeling. Journal of hazardous materials 2012, 209, 264-270.

46. Salam, H.A.; Sivaraj, R.; Venckatesh, R. Green synthesis and characterization of zinc oxide NPs from Ocimum basilicum L. var. purpurascens Benth.-Lamiaceae leaf extract. Materials letters 2014, 131, 16-18.

47. Selvarajan, E.; Mohanasrinivasan, V. Biosynthesis and characterization of ZnO NPs using Lactobacillus plantarum VITES07. Materials Letters 2013, 112, 180-182.

48. Jayappa, M.D.; Ramaiah, C.K.; Kumar, M.A.P.; Suresh, D.; Prabhu, A.; Devasya, R.P.; Sheikh, S. Green synthesis of zinc oxide NPs from the leaf, stem and in vitro grown callus of Mussaenda frondosa L.: characterization and their applications. Applied nanoscience 2020, 10, 3057-3074.

49. Karnan, T.; Selvakumar, S.A.S. Biosynthesis of ZnO NPs using rambutan (Nephelium lappaceumL.) peel extract and their photocatalytic activity on methyl orange dye. Journal of molecular Structure 2016, 1125, 358-365.

50. Jeevanandam, J.; Barhoum, A.; Chan, Y.S.; Dufresne, A.; Danquah, M.K. Review on NPs and nanostructured materials: history, sources, toxicity and regulations. Beilstein journal of nanotechnology 2018, 9, 1050-1074.

51. Gautam, S.K.; Sapkota, B.; Bhujel, A.; Bhattarai, S. Estimation of Particle Size and Band Gap of Zinc Oxide Nanoparticle Synthesized by Chemical Precipitation Method. Journal of Nepal Chemical Society 2020, 41, 46-50.

52. Rai, A.; Singh, A.; Ahmad, A.; Sastry, M. Role of halide ions and temperature on the morphology of biologically synthesized gold nanotriangles. Langmuir 2006, 22, 736-741. 
53. Das, A.K.; Marwal, A.; Verma, R. Bio-reductive synthesis and characterization of plant protein coated magnetite NPs. Nano Hybrids and Composites 2014, 7, 69.

54. Moldovan, B.; Sincari, V.; Perde-Schrepler, M.; David, L. Biosynthesis of silver NPs using Ligustrum ovalifolium fruits and their cytotoxic effects. Nanomaterials 2018, 8 , 627.

55. Elumalai, K.; Velmurugan, S. Green synthesis, characterization and antimicrobial activities of zinc oxide NPs from the leaf extract of Azadirachta indica (L.). Applied Surface Science 2015, 345, 329-336.

56. Kavitha, M.; John, H.; Gopinath, P.; Philip, R. Synthesis of reduced graphene oxide-ZnO hybrid with enhanced optical limiting properties. Journal of Materials Chemistry C 2013, $1,3669-3676$.

57. Awwad, A.M.; Amer, M.W.; Salem, N.M.; Abdeen, A.O. Green synthesis of zinc oxide NPs (ZnO-NPs) using Ailanthus altissima fruit extracts and antibacterial activity. Chem. Int 2020, 6, 151-159.

58. Yusof, H.M.; Mohamad, R.; Zaidan, U.H.; Samsudin, A.A. Biosynthesis of zinc oxide NPs by cell-biomass and supernatant of Lactobacillus plantarum TA4 and its antibacterial and biocompatibility properties. Scientific Reports 2020, 10, 1-13.

59. Markus, J.; Mathiyalagan, R.; Kim, Y.-J.; Abbai, R.; Singh, P.; Ahn, S.; Perez, Z.E.J.; Hurh, J.; Yang, D.C. Intracellular synthesis of gold NPs with antioxidant activity by probiotic Lactobacillus kimchicus DCY51T isolated from Korean kimchi. Enzyme and microbial technology 2016, 95, 85-93.

60. Degen, A.; Kosec, M. Effect of $\mathrm{pH}$ and impurities on the surface charge of zinc oxide in aqueous solution. Journal of the European Ceramic Society 2000, 20, 667-673.

61. An, C.; Peng, S.; Sun, Y. Facile synthesis of sunlight-driven AgCl: Ag plasmonic nanophotocatalyst. Advanced Materials 2010, 22, 2570-2574.

62. Suwanchawalit, C.; Wongnawa, S. Influence of calcination on the microstructures and photocatalytic activity of potassium oxalate-doped $\mathrm{TiO} 2$ powders. Applied Catalysis A: General 2008, 338, 87-99.

63. Castillo, N.C.; Heel, A.; Graule, T.; Pulgarin, C. Flame-assisted synthesis of nanoscale, amorphous and crystalline, spherical BiVO4 with visible-light photocatalytic activity. Applied Catalysis B: Environmental 2010, 95, 335-347.

64. Li, F.-t.; Zhao, Y.; Liu, Y.; Hao, Y.-j.; Liu, R.-h.; Zhao, D.-s. Solution combustion synthesis and visible light-induced photocatalytic activity of mixed amorphous and crystalline MgAl2O4 nanopowders. Chemical Engineering Journal 2011, 173, 750-759. 
65. Wang, F.; Min, S.; Han, Y.; Feng, L. Visible-light-induced photocatalytic degradation of methylene blue with polyaniline-sensitized $\mathrm{TiO} 2$ composite photocatalysts. Superlattices and Microstructures 2010, 48, 170-180.

66. Li, X.; Liu, G.; Zhao, J. Two competitive primary processes in the photodegradation of cationic triarylmethane dyes under visible irradiation in $\mathrm{TiO} 2$ dispersions. New Journal of Chemistry 1999, 23, 1193-1196.

67. Lachheb, H.; Puzenat, E.; Houas, A.; Ksibi, M.; Elaloui, E.; Guillard, C.; Herrmann, J.-M. Photocatalytic degradation of various types of dyes (Alizarin S, Crocein Orange G, Methyl Red, Congo Red, Methylene Blue) in water by UV-irradiated titania. Applied Catalysis B: Environmental 2002, 39, 75-90.

68. Hu, C.; Jimmy, C.Y.; Hao, Z.; Wong, P.K. Photocatalytic degradation of triazinecontaining azo dyes in aqueous $\mathrm{TiO} 2$ suspensions. Applied Catalysis B: Environmental 2003, 42, 47-55.

69. Eskizeybek, V.; Sarı, F.; Gülce, H.; Gülce, A.; Avc1, A. Preparation of the new polyaniline/ZnO nanocomposite and its photocatalytic activity for degradation of methylene blue and malachite green dyes under UV and natural sun lights irradiations. Applied Catalysis B: Environmental 2012, 119, 197-206.

70. Kitture, R.; Koppikar, S.J.; Kaul-Ghanekar, R.; Kale, S. Catalyst efficiency, photostability and reusability study of ZnO NPs in visible light for dye degradation. Journal of physics and chemistry of solids 2011, 72, 60-66. 